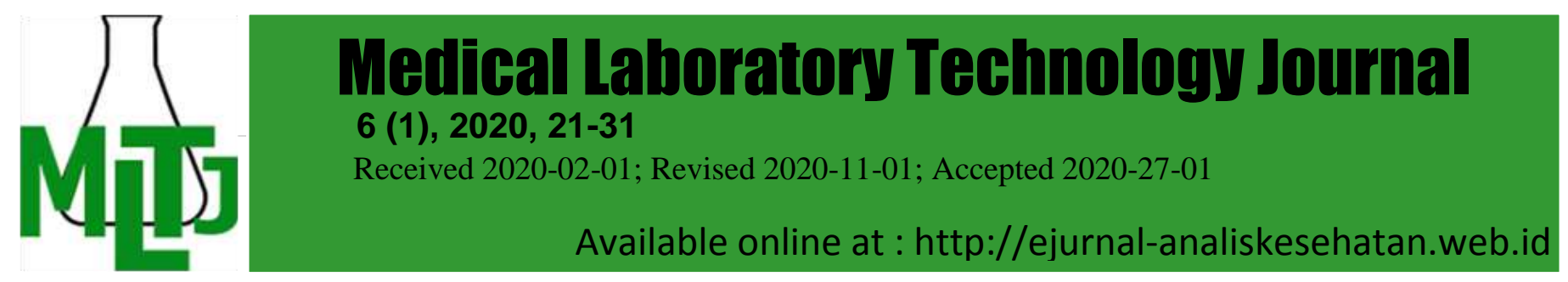

\title{
Renal Function Evaluation in Secondary Amyloidosis According to Location of Deposition
}

\author{
*Serhat Özçelik', Gülizar Manga Şahin² \\ ${ }^{1}$ University of Health Sciences Kartal Dr. Lütfi Kırdar Training and Research \\ Hospital, Department of Endocrinology and Metabolism, İstanbul, Turkey \\ ${ }^{2}$ University of Health Sciences Sultan Abdülhamid Han Training and Research \\ Hospital, Department of Nephrology ,Istanbul, Turkey. \\ *Email: ozserhat1981@gmail.com \\ DOI: 10.31964/mltj.v1i1.284
}

\begin{abstract}
It aimed to evaluate the renal functions according to the accumulation site of amyloid in patients diagnosed with secondary amyloidosis by renal biopsy. Fifty patients diagnosed with secondary amyloidosis, who referred to the nephrotic syndrome outpatient clinic included in the study. According to the findings of renal biopsy, only-glomerular amyloid deposition (group-1) detected in 9 patients and glomerular+ tubulointerstitial deposition (group- 2) identified in 41 patients. Serum creatinine, creatinine clearance, and total proteinuria levels compared between groups at the time of presentation and on 3rd, 6th, 12th, and 24th months. Initial and subsequent serum creatinine, creatinine clearance, and total proteinuria levels not found to be significantly different between groups ( $p>0,05$ for all). Among subjects with only-glomerular deposition, statistically significant descents in total proteinuria, when compared to initial levels, were observed from the beginning of the 6th month to the end of the 24th month $(p<0,05)$. On the other hand, subjects with both glomerular + tubulointerstitial deposition, statistically significant descents in total proteinuria levels observed from the beginning of follow-up to the end of the 24th month $(p<0,01)$. In subjects with both glomerular + tubulointerstitial accumulation, a statistically significant increase in serum creatinine, compared to baseline levels, observed in 12th and 24th months $(p<0,01)$. According to the biopsy findings, progressive deterioration of renal functions and an increase in proteinuria were higher in patients with both glomerular and tubulointerstitial amyloid deposition than patients with only-glomerular removal.
\end{abstract}

Keywords: renal biopsy; deposition; secondary amyloidosis

\section{INTRODUCTION}

Amyloidosis is a disease caused by the extracellular accumulation of a fibrillary protein called amyloid in various organs (Westermark et al., 2005). Amyloid fibrils may be stored locally and involve almost all organ systems depending on the biochemical structure of the amyloid precursor proteins. Amyloid fibril deposition may not lead to any significant clinical manifestations, but on the other hand, it may accompany severe pathophysiological changes, as well. The disease usually progresses between these two extremes (Husby et al.,1994 ). Despite technological advances, no clinical, serological, or radiological data have fully substituted renal biopsy for the identification of amyloidosis ( Pepys et al.,2001 and Kebbel et al., 2006 and Bergesio et al., 2007 and Lachmann et al., 2004 ). After the diagnosis of amyloidosis, the determination of amyloid type is essential in terms of treatment and

Corresponding Author: Serhat Özçelik

University of Health Sciences Kartal Dr. Lütfi Kırdar Training and Research Hospital, Department of Endocrinology and Metabolism, İstanbul, Turkey.

Email: ozserhat1981@gmail.com 
prognosis of the disease (Picken et al., 2007 ). Secondary (reactive, modified, or AA) amyloidosis most commonly occurs during chronic inflammatory diseases, infections, and neoplastic diseases. Familial Mediterranean fever (FMF), chronic obstructive pulmonary disease (COPD), rheumatoid arthritis, ankylosing spondylitis, systemic lupus erythematosus, behçet's disease, Crohn's disease, and ulcerative colitis are among the most common chronic inflammatory diseases. At the same time, tuberculosis, osteomyelitis, and bronchiectasis are the frequent infectious and thyroid medullary cancer, Hodgkin lymphoma and insulinoma are the numerous neoplastic causes (Cohen et al., 1991 and Seldin et al., 2005 and Falk et al., 1997 and Elżbieta et al., 2019 ). Renal involvement in systemic amyloidosis is a common complication and indicates a poor prognosis. Patients present with clinical manifestations ranging from proteinuria to nephrotic syndrome, and renal biopsy is required in a significant proportion of patients to serve as a diagnostic and also a prognostic tool. Therefore, the clinical correlation with the storage type, severity, prevalence and clinical reflection of the kidney biopsy will enable the prognosis of the disease to predicted (Lachmann et al., 2004 and Falk et al., 1997 and Elżbieta et al., 2019 and Lachmann et al., 2007 and Gertz et al., 1991 ).

The distribution pattern of glomerular amyloid deposits, glomerular inflammatory reaction, and tubular atrophy in the renal biopsy are independent risk factors for proteinuria level and renal damage (Verine et al., 2007 ). Renal failure usually refers to severe glomerular amyloidosis and tubular atrophy. In contrast, renal prognosis in patients with renal amyloidosis does not always have a morphological explanation (Dikman et al., 1981). To understand how this clinical difference occurs, we wanted to clarify the results of amyloid deposition, especially in the glomerular and tubulointerstitial space. This study aimed to evaluate the renal biopsy findings for the amyloid storage location and according to renal functions of patients with secondary amyloidosis.

\section{MATERIALS - METHODS}

\section{Patient population and follow-up}

Fifty patients admitted to the nephrotic syndrome outpatient clinic of İstanbul Göztepe Training and Research Hospital from 1994 to 2010 and diagnosed with secondary amyloidosis after undergoing renal biopsy included in the study. The ethics committee approved the review of İstanbul Göztepe Training and Research Hospital. Age, sex, serum urea, creatinine, 24-hour urine total protein (glomerular filtration rate, clinical signs at presentation (such as edema, hematuria, proteinuria, oligoanurated hypertension) and an indication of renal biopsy (nephrotic syndrome, nephritic syndrome and asymptomatic urine findings, etc.) were collected retrospectively. Serum urea, creatinine, and 24 -hour urine total protein performed by photometric measurement methods (Architect C16000 clinical biochemistry analyzer, Abbott $\AA$, USA). In calculating the glomerular filtration rate, the formula proposed by the Study Group's Modification of Diet in Renal Disease (MDRD) was used ( Levey et al., 1999 ). The relevant medical history like underlying chronic diseases (FMF, COPD, rheumatoid arthritis, Behçet's disease, ankylosing spondylitis, bronchiectasis, and tuberculosis, etc.) and currently used antiproteinuric drugs (angiotensinconverting enzyme inhibitors (ACEi) and angiotensin receptor blockers (ARB) provided.

Renal biopsy report of each case obtained and findings of glomerular involvement, tubular involvement, tubular atrophy, and interstitial fibrosis recorded. Based on renal biopsy, amyloid involvement dichotomized into two groups according 
to whether the involved compartment was only-glomeruli (Group-1) or both glomeruli and tubulointerstitium (Group-2). Stage 1, in the scoring system of renal amyloidosis, corresponds to Group-1 in our study, whereas stage 2 and 3 match with group-2 (Sen et al., 2010).

The follow-up time started from the month of renal biopsy (baseline) and continued with data collection on 3rd, 6th, 12th, and 24th months. The final status of the patients, including active disease, remission (complete and partial), and relapse, was considered to evaluate prognosis and treatment outcome (Table-1).

Table-1: Active, remission and relapse criteria of the disease

\begin{tabular}{ll}
\hline Active proteinuria & Proteinuria over $3.5 \mathrm{~g} /$ day on 3 consecutive days \\
Complete remission & Less than $0.2 \mathrm{~g} /$ day of proteinuria for 3 consecutive days \\
Partial remission & $\begin{array}{l}\text { Proteinuria between } 0.2-3.5 \mathrm{~g} / \mathrm{day} \text { for } 3 \text { consecutive days } \\
\text { In patients at complete remission, proteinuria over } 0.2 \mathrm{~g} / \mathrm{day}\end{array}$ \\
$\begin{array}{l}\text { Proteinuria relapse } \\
\text { for at least one week }\end{array}$ & $\begin{array}{l}\text { Proteinuria more significant than } 3.5 \mathrm{~g} / \text { day for at least one } \\
\text { relapse syndrome in patients at complete or partial remission }\end{array}$ \\
\hline
\end{tabular}

\section{Pathology}

The following morphological findings used in Group-1 and Group-2 classification:

1-Amyloid involvement of the glomerular compartment (total number of glomeruli, number of globally sclerotic glomeruli, glomerular participation type, a diameter of glomeruli, degree of glomerular amyloid, accumulation of glomerular nodular amyloid (segmental/global presence)

2-Amyloid involvement of the tubular-interstitial compartment (vasa recta involvement, tubular atrophy/fibrosis, appearance, quality and severity of interstitial inflammation, accumulation and diameter of interstitial amyloid, amyloid deposition in the tubular basement membrane damage)

\section{Statistical analysis}

NCSS (Number Cruncher Statistical System) 2007 \& PASS 2008 Statistical Software (Utah, USA) program used for statistical analysis. The normality of distribution examined by using the Kolmogorov-Smirnov test. Along with descriptive statistical methods (mean, standard deviation), for comparison of quantitative and normally distributed data. Although normal distribution was determined, nonparametric tests used due to the relatively small sample size. Mann-Whitney U t-test used for between-group differences. Wilcoxon Signed Ranks test used for withingroup differences. The chi-square test used to evaluate the qualitative data. Significance was assessed at $p<0.05$.

\section{RESULTS AND DISCUSSION}

\section{Baseline characteristics and morphological findings}

The mean age at the time of diagnosis was 46.92(13.3) years (M: $F=1.27: 1$ ). The most common cause of secondary amyloidosis was FMF, followed by COPD and rheumatoid arthritis (Table-2). While only glomerular involvement detected in 9 of 50 cases (Group-1), 41 of them had both glomerular and tubulointerstitial relationships (Group-2). Glomerulosclerosis was observed in 17 of the cases, while mesangial proliferation and inflammatory cells in the glomeruli observed in the remaining 33 cases. Tubular atrophy (82\%) was common and mostly mild $(76 \%)$. 
Inflammatory reaction was present in $32 \%$ of the cases; inflammatory cells were generally of the mixed (mononuclear + polymorphonuclear) type.

Table 2: Diseases causing AA (Secondary) amyloidosis

\begin{tabular}{llll}
\hline & \multicolumn{3}{c}{ Biopsy Finding } \\
Underlying Chronic Disease & Group-1 & Group-2 & Total \\
& $\mathrm{n}: 9(\%)$ & $\mathrm{n}: 41(\%)$ & $\mathrm{n}: 50(\%)$ \\
\hline FMF & $8(88,9 \%)$ & $20(48,8 \%)$ & $28(56,0 \%)$ \\
COPD & $0(\% 0)$ & $8(19,5 \%)$ & $8(16,0 \%)$ \\
Romatoid artrit & $1(11,1 \%)$ & $5(12,2 \%)$ & $6(12,0 \%)$ \\
Ankylosing spondylitis & $0(0 \%)$ & $2(4,9 \%)$ & $2(4,0 \%)$ \\
Gout & $0(0 \%)$ & $2(4,9 \%)$ & $2(4,0 \%)$ \\
Chronic pyelonephritis & $0(0 \%)$ & $2(4,9 \%)$ & $2(4,0 \%)$ \\
Tuberculosis & $0(0 \%)$ & $2(4,9 \%)$ & $2(4,0 \%)$ \\
Behcet 's disease & $0(0 \%)$ & $1(2,4 \%)$ & $1(2,0 \%)$ \\
Hodgkin Lymphoma & $0(0 \%)$ & $1(2,4 \%)$ & $1(2,0 \%)$ \\
Ulcerative colitis & $0(0 \%)$ & $1(2,4 \%)$ & $1(2,0 \%)$ \\
\hline
\end{tabular}

FMF; familial mediterranean fever

COPD; Chronic obstructive pulmonary diseases

\section{Clinicopathological correlation \\ Total proteinuria}

There was no statistically significant change in total proteinuria in the 3rd month, compared to baseline, in Group-1 patients ( $p>0.05$ ). However, when the absolute proteinuria values examined from the beginning of the 6th month to the end of the 24th month, statistically significant decreases compared to baseline were observed $(p<0,05)$. About group-2, statistically, significant descents in total proteinuria levels were seen from the beginning of follow-up to the end of the 24th month $(p<0,01)$. There was no significant difference between the groups $(p>0,05)$ (Table-3, Figure-1).

Table 3: Evaluation of Total Proteinuria ( $\mathrm{mg} / 24 \mathrm{~h}$ ) based on Biopsy Finding

\begin{tabular}{llll}
\hline \multirow{3}{*}{ Total Proteinuria $(\mathrm{mg} / 24 \mathrm{~h})$} & \multicolumn{3}{l}{ Biopsy Finding } \\
& Group-1 & Group-2 & \multirow{2}{*}{$p^{*}$} \\
& Mean $\pm \mathrm{SD}$ & Mean $\pm \mathrm{SD}$ & \\
\hline Baseline & $5,11 \pm 5,17$ & $4,71 \pm 3,46$ & 0,785 \\
3rd month & $2,45 \pm 2,54$ & $3,78 \pm 2,84$ & 0,160 \\
6th month & $1,88 \pm 1,77$ & $3,92 \pm 3,54$ & 0,119 \\
12 th month & $1,78 \pm 2,07$ & $3,35 \pm 3,21$ & 0,091 \\
24 th month & $1,41 \pm 1,69$ & $2,94 \pm 2,76$ & 0,082 \\
\hline Baseline-3rd month & 0,086 & 0,031 & \\
Baseline-6th month & $0,028^{*}$ & 0,048 & \\
Baseline-12th month & $0,028^{*}$ & 0,048 & \\
Baseline-24th month & $0,018^{*}$ & 0,002 & \\
\hline
\end{tabular}

${ }^{*}$ Mann-Whitney U t-test was used for between-group differences. Wilcoxon Signed Rank test was used for within-group differences. 
Figure-1: Total proteinuria (gr / $24 \mathrm{~h}$ ) levels by months

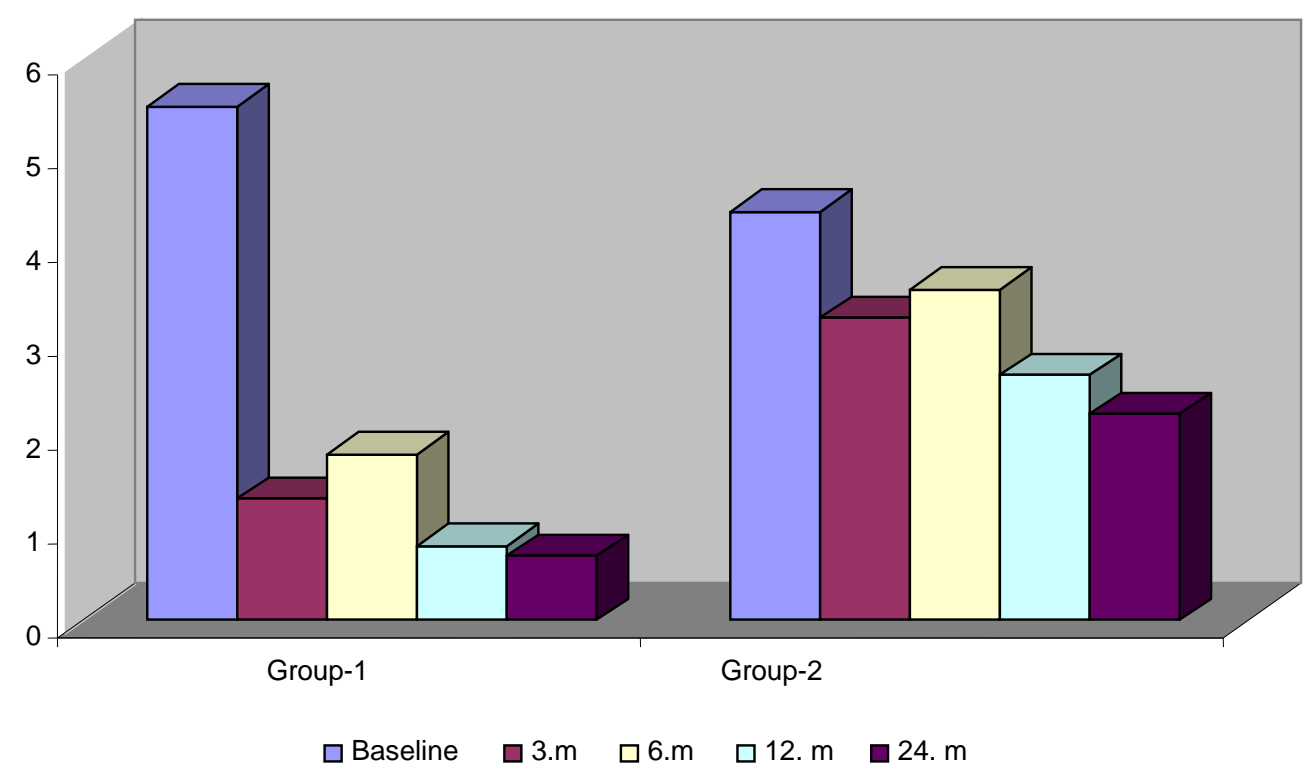

\section{Serum creatinine levels}

There was no statistically significant change in creatinine levels in Group-1 patients at the 3rd, 6th, 12th, and 24th months compared to baseline ( $p>0.05)$. Regarding the change in creatinine levels in group-2 patients, there was no significant difference ( $p>0.05$ ) between baseline and 3rd and 6th months. On the contrary, in the 12th and 24th months, a statistically significant rise in creatinine was seen compared to baseline levels $(p<0.01)$.

\section{Glomerular filtration rate}

Twelve percent of all cases had an end-stage renal failure at the time of renal biopsy. In Group-1, there was no statistically significant change in MDRD GFR between the baseline and the 3rd, 6th, 12th, and 24th months' rates ( $p>0.05)$. However, MDRD GFR significantly decreased in Group-2 cases at 12th and 24th months compared to baseline ( $p>0.05)$ (Table -4 and Figure-2)

Figure-2: MDRD GFR (mL / min / $1.73 \mathrm{~m} 2)$ changes by months

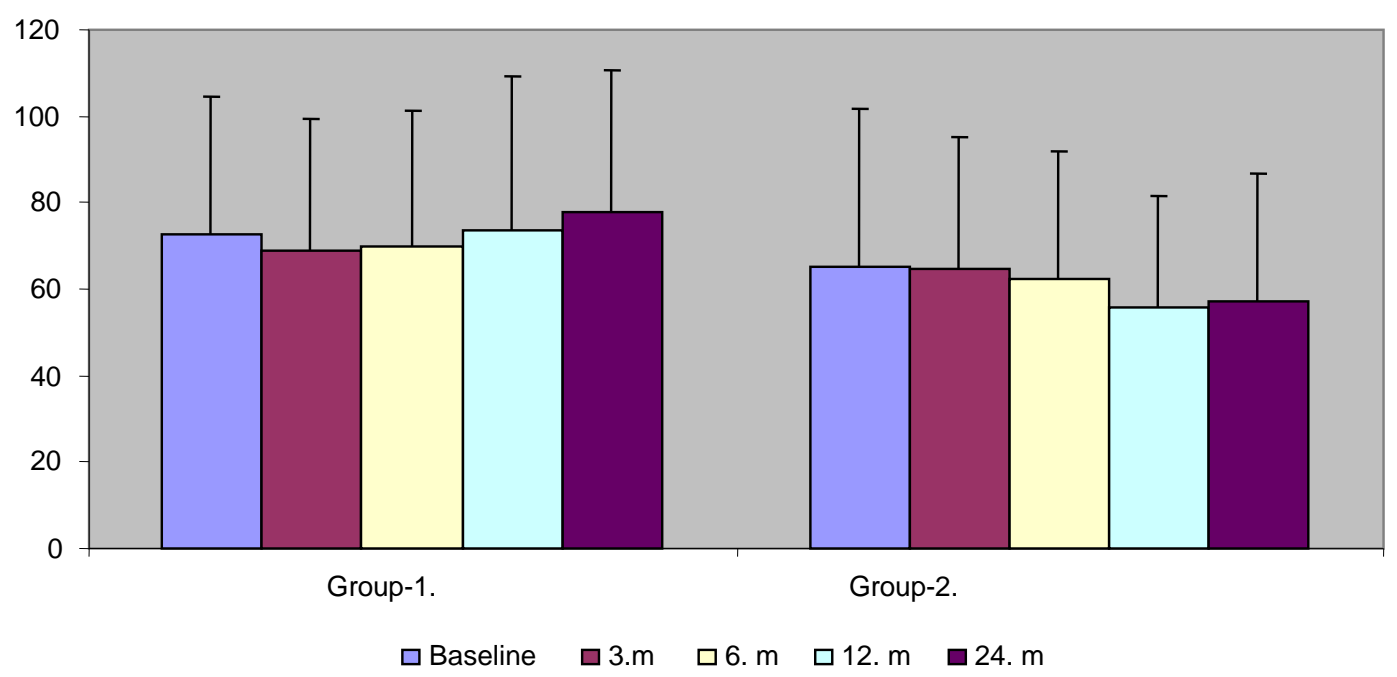


Table 4: Evaluation of MDRD GFR ( $\mathrm{mL} / \mathrm{min} / 1.73 \mathrm{~m} 2)$

\begin{tabular}{llll}
\hline \multirow{2}{*}{ MDRD GFR } & \multicolumn{3}{c}{ Biopsy Finding } \\
& $\begin{array}{l}\text { Group-1 } \\
\text { Mean } \pm \text { SD }\end{array}$ & $\begin{array}{l}\text { Group-2 } \\
\text { Mean } \pm \text { SD }\end{array}$ & $p^{*}$ \\
\hline Baseline & $72,67 \pm 32,05$ & $65,34 \pm 30,61$ & 0,522 \\
3rd month & $68,89 \pm 36,61$ & $64,90 \pm 30,05$ & 0,730 \\
6th month & $69,78 \pm 31,24$ & $62,53 \pm 29,47$ & 0,512 \\
12th month & $73,67 \pm 35,47$ & $55,85 \pm 25,81$ & 0,087 \\
24th month & $71,87 \pm 32,74$ & $57,25 \pm 29,57$ & 0,084 \\
\hline Baseline-3rd month & 0,268 & 0,815 & \\
Baseline-6th month & 0,531 & 0,102 & \\
Baseline-12th month & 0,740 & 0,001 & \\
Baseline-24th month & 0,953 & 0,009 & \\
\hline
\end{tabular}

MDRD GFR; Modification of Diet in Renal Disease glomerular filtration rate.

*Mann-Whitney U t-test was used for between-group differences.

Wilcoxon Signed Rank test was used for within-group differences

\section{Drugs used}

Use of ACEi, ARB and the combination of ACEi and ARB as anti-proteinuric treatment were compared between groups and not found to be statistically significant (Table-5).

Table 5: Use of ACEi, ARB and ACEi + ARB combination

\begin{tabular}{|c|c|c|c|c|}
\hline & & \multicolumn{3}{|c|}{ Biopsy Finding } \\
\hline & & $\begin{array}{l}\text { Group-1 } \\
n(\%)\end{array}$ & $\begin{array}{l}\text { Group-2 } \\
n(\%)\end{array}$ & $P^{*}$ \\
\hline \multirow{3}{*}{$\begin{array}{l}\text { Baseline } \\
\text { treatment }\end{array}$} & ACE & $4(50 \%)$ & $26(66,7 \%)$ & \multirow{3}{*}{0,575} \\
\hline & ARB & $1(12,5 \%)$ & $5(12,8 \%)$ & \\
\hline & $\mathrm{ACE}+\mathrm{ARB}$ & $3(37,5 \%)$ & $8(20,5 \%)$ & \\
\hline \multirow{3}{*}{$\begin{array}{l}\text { 3rd month } \\
\text { treatment }\end{array}$} & ACE & $3(33,3 \%)$ & $23(57,5 \%)$ & \multirow{3}{*}{0,265} \\
\hline & ARB & $1(11,1 \%)$ & $6(15 \%)$ & \\
\hline & $A C E+A R B$ & $5(55,6 \%)$ & $11(27,5 \%)$ & \\
\hline \multirow{3}{*}{$\begin{array}{l}\text { 6th month } \\
\text { treatment }\end{array}$} & ACE & $3(33,3 \%)$ & $22(56,4 \%)$ & \multirow{3}{*}{0,362} \\
\hline & ARB & $1(11,1 \%)$ & $5(12,8 \%)$ & \\
\hline & $A C E+A R B$ & $5(55,6 \%)$ & $12(30,8 \%)$ & \\
\hline \multirow{3}{*}{$\begin{array}{l}\text { 12th month } \\
\text { treatment }\end{array}$} & ACE & $2(22,2 \%)$ & $17(43,6 \%)$ & \multirow{3}{*}{0,457} \\
\hline & ARB & $2(22,2 \%)$ & $8(20,5 \%)$ & \\
\hline & ACE+ARB & $5(55,6 \%)$ & $14(35,9 \%)$ & \\
\hline \multirow{3}{*}{$\begin{array}{l}\text { 24th month } \\
\text { treatment }\end{array}$} & ACE & $3(37,5 \%)$ & $17(47,2 \%)$ & \multirow{3}{*}{0,449} \\
\hline & ARB & $1(12,5 \%)$ & $9(25 \%)$ & \\
\hline & $\mathrm{ACE}+\mathrm{ARB}$ & $4(50 \%)$ & $10(27,8 \%)$ & \\
\hline
\end{tabular}

ACEi; angiotensin converting enzyme inhibitors,

ARB; angiotensin receptor blockers.

${ }^{*}$ Chi- square test was used for between-group differences 


\section{Evaluation of the final status}

During the renal biopsy, $46 \%$ of the patients were in remission (complete and partial), and $54 \%$ were inactive proteinuria phase. At the end of the 12 th month, $28 \%$ of patients had progressive proteinuria, $58 \%$ had a remission, $2 \%$ had proteinuria relapse, and $12 \%$ had nephrotic syndrome relapse. At the end of 24 months, the remission rate increased to $70 \%$ (12\% complete and $59 \%$ partial), while the actual proteinuria rate decreased to $18 \%$.

Among patients with only-glomerular involvement, $55.6 \%$ had progressive proteinuria at the time of biopsy. At the end of 24 months, all but one patient had complete or partial remission. In patients with both glomerular and tubulointerstitial involvement, $53.7 \%$ had progressive proteinuria at baseline while this rate was $36.6 \%$ at the end of the 3rd month, $31.7 \%$ at the end of the 6 th month, and $23.1 \%$ at the end of the 24th month. Finally, at the end of the 24th month, $69.2 \%$ of the patients were in remission (Table-6).

Table 6: Final Assessment of Proteinuria Levels

\begin{tabular}{|c|c|c|c|}
\hline & & & nding \\
\hline Final status & & Group-1 & Group-2 \\
\hline & & & \\
\hline & Actıve proteınuria & $5(\% 55,6)$ & $22(\% 53,7)$ \\
\hline Baseline & Complete remission & 0 & $1(\% 2,4)$ \\
\hline & Partial remission & $4(\% 44,4)$ & $18(\% 43,9)$ \\
\hline & Active proteinuria & $2(\% 22,2)$ & $15(\% 36,6)$ \\
\hline & Complete remission & $2(\% 22,2)$ & $1(\% 2,4)$ \\
\hline 3rd month & Partial remission & $5(\% 55,6)$ & $19(\% 46,3)$ \\
\hline & Proteinuria relapse & 0 & $1(\% 2,4)$ \\
\hline & NS relapse & 0 & $5(\% 12,2)$ \\
\hline & Active proteinuria & $1(\% 11,1)$ & $13(\% 31,7)$ \\
\hline Gth month & Complete remission & $2(\% 22,2)$ & $4(\% 9,8)$ \\
\hline otm month & Partial remission & $5(\% 55,6)$ & $19(\% 46,3)$ \\
\hline & NS relapse & $1(51,1)$ & $5(\% 12,2)$ \\
\hline & Active proteinuria & $1(\% 11,1)$ & $13(\% 31,7)$ \\
\hline & Complete remission & $1(\% 11,1)$ & $4(\% 9,8)$ \\
\hline 12th month & Partial remission & $5(\% 55,6)$ & $19(\% 46,3)$ \\
\hline & Proteinuria relapse & $1(\% 11,1)$ & 0 \\
\hline & NS relapse & $1(\% 11,1)$ & $5(\% 12,2)$ \\
\hline & Active proteinuria & 0 & $9(\% 23,1)$ \\
\hline & Complete remission & $3(\% 33,3)$ & $4(\% 9.7)$ \\
\hline 24th month & Partial remission & $5(\% 55,6)$ & $25(\% 60.9)$ \\
\hline & Proteinuria relapse & 0 & $1(\% 2,6)$ \\
\hline & NS relapse & $1(\% 11,1)$ & $2(\% 5,1)$ \\
\hline
\end{tabular}

NS; Nephrotic syndrome

In this study involving patients diagnosed with secondary amyloidosis, kidney functions were evaluated according to the renal amyloid storage location, whether in only-glomerular or both glomerular+tubulointerstitial compartment, in 24 months. In the end, no significant difference found about serum creatinine, MDRD creatinine 
clearance, and total proteinuria levels between the predefined groups. However, within each group, throughout 24 months, in comparison to the baseline month, the renal loss was found to be higher in glomeruli + tubulointerstitium-involved patients compared to only-glomeruli-involved patients. It is also noteworthy to state that a considerable proportion of the patients (56\%) with secondary amyloidosis had to coexist FMF in the present study emphasizing the relatively high frequency of this disease in Turkey.

The number of studies in the literature on the amount and localization of amyloid stored in the kidney is limited (Shiiki et al., 1988 and Watanabe et al., 1975 and Falck et al., 1983; and Westermark et al., 1979). Existing studies on morphological findings predicting proteinuria levels in secondary amyloidosis have been established linear correlation with the severity of glomerular amyloid deposition (Verine et al., 2007 and Kaplan et al., 1999). Proteinuria severity correlates with the presence of podocyte destruction rather than the amount of amyloid in the glomeruli (Dikman et al., 1981 ). In our study, although glomerular and tubulointerstitial involvement not evaluated separately, there was a numerical difference between the groups in terms of total proteinuria decrease. Although this situation was not statistically significant, the decline compared to baseline was approximately 3.5 times for group 1 and less than half for group 2. In a study, closely resembling our sample size and primary etiology, the results of renal function change and proteinuria reduction found to be similar. (Abdallah et al., 2013). While evaluating these changes in proteinuria levels, intensive use of $A C E i, A R B$, or $A C E i$, together with $A R B$, should not be ignored in both study groups. In a study where ACEi (ramipril) and ARB (telmisartan) were used together as a dual effect, or only ACEi or ARB used as monotherapy, a significantly higher incidence of hyperkalemia observed in the double blockage arm. ( Heerspink et al., 2014). Currently, the combination of ACEi and ARB is no longer in use because of the considerable risk of hyperkalemia. Since the study covers the years 1994-2010, the combination therapy had used in Turkey at that time.

Dikman et al. reported a rapid loss of renal function in patients with renal amyloidosis with tubular atrophy (Dikman et al., 1981). Verine et al. also regarded the tubular atrophy and the prevalence and type of amyloid deposition as independent variables for renal function (Verine et al., 2007 ). Supporting these trials, in the present study, glomerular amyloid deposition coupled with tubulointerstitial involvement, which defined as group-2, exhibited a prominent renal loss, particularly after 1st year in the follow-up. However, in the study arm with onlyglomerular responsibility, the renal reserve was better preserved.

Results from analysis, including 97 patients with primary and secondary amyloidosis, ended up with a five and 10-year survival rate of $30 \%$ and $20 \%$, respectively. The authors concluded that the strongest prognostic determinants of renal survival are amyloid-induced renal damage and serum creatinine level at the time of biopsy. Furthermore, AA amyloidosis found to be far more associated with tubulointerstitial loss as compared to AL amyloidosis (Sasatomi et al., 2001 ). However, Dikman et al. argued that there is not always a morphological explanation for the frequently irreversible decrease in renal function (Dikman et al., 1981). This may be a result of the rate of development of amyloidosis, they added. Because the risk and price of development of amyloidosis vary according to genotypes (Nakamura et al., 2006), nevertheless, a recent article uncovered the conclusion that renal damage not expected to be associated with amyloid deposition (Kuroda et al., 2017 and Kuroda et al., 2019). 
Selection bias resulting from retrospective work is our main limitation. The other limitation is the small number of patients included. The third one is the lack of standardization in the antiproteinuric treatment agents among patients and last relates to the absence of rebiopsies during the follow-up, to determine whether a non-glomerular involvement occurs in group-1.

\section{CONCLUSION}

According to the biopsy findings, progressive deterioration of renal functions and an increase in proteinuria were higher in patients with both glomerular and tubulointerstitial amyloid deposition than patients with only-glomerular removal. Therefore the pathology report in patients with renal amyloidosis should incorporate detailed morphological findings aiding better prognostication (the type of glomerular amyloid accumulation and renal damage score = degree of glomerular accumulation + tubulointerstitial accumulation) rather than be used as a general diagnostic assay.

\section{ACKNOWLEDGMENTS}

There were no external sources of funding for this study.

\section{CONFLICT OF INTEREST}

The authors have declared that they have no significant relationships with or financial interests in any commercial company.

\section{REFERENCES}

Westermark P, Benson MD, Buxbaum JN, Cohen AS, Frangione B, Ikeda S, et al. (2005) Amyloid: toward terminology clarification. Report from the Nomenclature Committee of the International Society of Amyloidosis. Amyloid, 12(1), 1-4.

Husby G, Marhaug G, Dowtor B, Sletten K, Sipe JD. (1994). Serum amyloid A (SAA): Biochemistry, genetics and the pathogenesis of AA amyloidosis. Amyloid (1),119-137

Pepys MB. (2001). Pathogenesis, diagnosis and treatment of systemic amyloidosis. Philos Trans $R$ Soc Lond B Biol Sci, 356(1406), 203-210

Kebbel A, Röcken C. (2006). Immunohistochemical classification of amyloid in surgical pathology revisited. Am J SurgPathol. 30(6), 673-683.

Bergesio F, Ciciani AM, Santostefano M, Brugnano R, Manganaro M, Palladini G, et al. (2007). Renal involvement in systemic amyloidosis--an Italian retrospective study on epidemiologica land clinical data at diagnosis. Nephrol Dial Transplant, 22(6), 1608-1618.

Lachmann HJ, Goodman HJB, Gallimore J. (2004). Characteristic and clinical outcome on 340 patients with systemic AA amyloidosis. Amyloid and Amyloidosis: France 10th International Symposium on Amyloidosis, 173-175.

Picken MM. (2007). New insights into systemic amyloidosis: the importance of diagnosis of specific type. Curr Opin Nephrol Hypertens, 16(3), 196-203

Cohen AS. (1991). Amyloidosis. Bull rheum Dis 40(2), 1-12

Seldin DC, Skinner M. (2005). Amyloidosis. Kelley 's Textbook of Rheumatology, Philadelphia : 1697 -1704 Elsevier Saunders

Falk RH, Comenzo RL, Skinner M. (1997). The systemic amyloidoses. $N$ engl $J$ med 337: 898 
Elżbieta SG, Marta P, Henryk K, Hanna W, Jerzy C, Michał H. (2019). Kidney amyloidosis in patients with systemic lupus erythematosus. Pol Arch Intern 129(11), 817-818

Lachmann HJ, Goodman HJ, Gilbertson JA, Gallimore JR, Sabin CA, Gillmore JD, et al. (2007). Natural history and outcome in systemic AA amyloidosis. $N$ Engl $J$ Med, 356(23), 2361-2371.

Gertz MA, Kyle RA. (1991). Secondary systemic amyloidosis: response and survival in 64 patients. Medicine (Baltimore), 70(4), 246-256.

Verine J, Mourad N, Desseaux K, Vanhille P, Noël LH, Beaufils H., et al . (2007). Clinical and histological characteristics of renal AA amyloidosis: a retrospective study of 68 cases with a special interest to amyloid-associated inflammatory response. Hum Pathol, 38(12), 1798-1809

Dikman SH, Churg J, Kahn T. (1981). Morphologic and clinical correlates in renal amyloidosis. Hum Pathol, 12(2), 160-169.

Levey AS, Bosch JP, Lewis JB, Greene T, Rogers N, Roth D. (1999). A more accurate method to estimate glomerular filtration rate from serum creatinine: a new prediction equation. Modification of Diet in Renal Disease Study Group. Ann Intern Med. 16;130(6), 461-470.

Sen S, Sarsik B. (2010). A proposed histopathologic classification, scoring, and grading system for renal amyloidosis: standardization of renal amyloid biopsy report. Arch Pathol Lab Med, 134(4), 532-544

Shiiki H, Shimokama T, Yoshikawa Y, Toyoshima H, Kitamoto T, Watanabe T. (1988). Renal amyloidosis. Correlations between morphology, chemical types of amyloid protein and clinical features. Virchows Arch A Pathol Anat Histopathol, 412(3), 197-204.

Watanabe T, Saniter T. (1975). Morphological and clinical features of renal amyloidosis. Virchows Arch A Pathol Anat Histol, 366(2), 125-135.

Falck HM, Tornroth T, Wegelius O. (1983). Predominantly vascular amyloid deposition in the kidney in patients with minimal or no proteinuria. Clin Nephrol, 19(3), 137-142.

Westermark, P, Sletten K, Eriksson M. (1979). Morphologic and chemicalvariation of the kidney lesions in amyloidosis secondary to rheumatoid arthritis. Lab Invest 41(5), 427-431.

Kaplan B, Hrncic R, Murphy CL, Gallo G, Weiss DT, Solomon A. (1999). Micro extraction and purification techniques applicable to chemical characterization of amyloid proteins in minute amounts of tissue. Methods in Enzymology, 306: $67-81$.

Heerspink HJ, Gao P, de Zeeuw D, Clase C, Dagenais GR, Sleight $P$,. et al ( 2014). The effect of ramipril and telmisartan on serum potassium and its association with cardiovascular and renal events: results from the Ontarget trial, 21(3), 299-309

Abdallah E, Waked E. (2013). Incidence and clinical outcome of renal amyloidosis: a retrospective study. Saudi J Kidney Dis Transpl, (5), 950-958.

Sasatomi Y, KiyoshiY, Uesugi N, Hisano S, Takebayashi S. (2001). Prognosis of renal amyloidosis: a clinicopathological study using cluster analysis. Nephron, 87, 42-49.

Nakamura T, Higashi S, Tomoda K, Tsukano M, Baba S, Shono M. (2006). Significance of SAA1.3 allele genotype in Japanese patients with amyloidosis secondary to rheumatoid arthritis. Rheumatology, 45, 43-49 
Kuroda T, Tanabe N, Hasegawa E, Wakamatsu A, Nozawa Y, Sato H., et al. (2017). Significant association between renal function and area of amyloid deposition in kidney biopsy specimens in both AA amyloidosis associated with rheumatoid arthritis and AL amyloidosis. Amyloid, 24(2), 123-130

Kuroda T, Ito Y, Imai N, Nozawa Y, Sato H, Nakatsue T,. et al (2019). Significant association between renal function and area of amyloid deposition in kidney biopsy specimens from patients with AA amyloidosis associated with rheumatoid arthritis and AL amyloidosis. Amyloid, 26(sup1), 125-126. 